\title{
Taxing sugar-sweetened beverages: a survey of knowledge, attitudes and behaviours
}

\author{
Cheryl Rivard*, Danielle Smith, Susan E McCann and Andrew Hyland \\ Department of Health Behavior, Roswell Park Cancer Institute, Elm \& Carlton Streets, Buffalo, NY 14263, USA
}

Submitted 10 May 2011: Accepted 29 September 2011: First published online 24 January 2012

\begin{abstract}
Objective: To assess current beverage consumption patterns and anticipated reaction to an added $20 \%$ tax on these products.

Design: A random-digit dialled telephone interview lasting $20 \mathrm{~min}$ was administered to assess demographics, beverage consumption behaviours and intentions regarding consumption of sugar-sweetened beverages in the event of an additional tax on these beverages.

Setting: Respondents were recruited throughout the USA.

Subjects: The study included 592 adults.

Results: Sixty-nine per cent of respondents reported consuming at least one prepackaged sugar-sweetened beverage in the past week; those who consumed sugar-sweetened beverages averaged seven pre-packaged beverages per week. Ninety-one per cent knew that frequent consumption of soft drinks increases risk of obesity. Thirty-six per cent supported a tax on sugar-sweetened beverages with greatest support among those aged $18-24$ years, those with BMI $<30 \mathrm{~kg} / \mathrm{m}^{2}$ and those with higher levels of education $(P<0 \cdot 05)$. Over one-third of respondents said that they would cut back on their sweetened beverage consumption in the event of an added $20 \%$ tax on these beverages.

Conclusions: Our findings suggest that an added tax on these beverages could influence some to cut down on their consumption, reducing their risk of obesity and related illnesses.
\end{abstract}

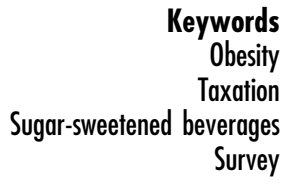

Obesity

Taxation

Survey
There is a substantial body of literature to support the adverse effects that obesity has on health, including increased risk of developing type 2 diabetes, CVD and high blood pressure ${ }^{(1,2)}$. Higher BMI $\left(\mathrm{kg} / \mathrm{m}^{2}\right)$ values have been associated with an increased risk for certain types of cancer including oesophageal adenocarcinoma and renal cancers in men and women, thyroid and colon cancers in men, and increased risk of endometrial and gallbladder cancers in women ${ }^{(3)}$. Additionally, the National Cancer Institute reports links between obesity and cancers of the breast (postmenopausal), ovary and pancreas ${ }^{(4)}$. Health problems resulting from overweight and obesity have been connected with increasing health-care costs for all Americans, as well as increased federal and state taxes and other fiscal penalties ${ }^{(5)}$.

A number of lifestyle factors contribute to obesity. Lack of physical activity coupled with a diet high in fat and/or energy, especially energy-dense foods with little to no nutritional value, increase a person's risk of becoming overweight or obese ${ }^{(4,6-8)}$. Sugar-sweetened beverages (SSB) have been recognized in several studies as a potential contributor to becoming overweight or obese ${ }^{(6-8)}$. Soft drinks consumption in particular has been connected with increased energy intake ${ }^{(7)}$, especially among children and adolescents. The Centers for Disease Control and Prevention (CDC) cites research stating that soft drinks accounted for 12-13\% of energy intake for adolescents aged 14-17 years during 1994-1998 ${ }^{(8)}$. The reported relationships between SSB consumption and body weight are mixed, although this could be due in part to differences in study design ${ }^{(7)}$. SSB intake has also been connected with decreased consumption of milk, $\mathrm{Ca}$ and other nutrients ${ }^{(7)}$.

According to the CDC, SSB contribute an estimated $7 \%$ of total energy intake for Americans ${ }^{(8)}$. In fact, over $60 \%$ of US adults report daily consumption of SSB; the highest rates of consumption have been reported among racial and ethnic minorities and among persons with lower income $^{(9,10)}$. Rates of obesity have also been found to be higher among lower-income households and among racial and ethnic minorities ${ }^{(10,11)}$.

The CDC states that one way to curb consumption of SSB is to limit access to such beverages ${ }^{(8)}$. Those who have examined the effectiveness of public health intervention programmes targeted at reducing obesity have suggested that a part of eliminating access could be to impose a tax on these products, thus decreasing product demand $^{(12)}$. Many states already have existing taxes on $\mathrm{SSB}$, varying from state to state in the form of sales taxes 
on the beverages themselves or as taxes levied on distributors, manufacturers and wholesalers for syrups and packaging $^{(13)}$. As an example, rates of sales tax on the price of soda range, on average, from $5 \%$ to $7 \cdot 25 \%$, which studies have shown reduces consumption only by very modest amounts ${ }^{(13-15)}$. Other states exclude SSB from taxation along with other foods ${ }^{(15)}$. Larger specific excise taxes on other products have proved successful in lowering demand for those products; for example, high excise taxes on cigarettes have in turn have led to many smokers to quit. Increased taxes on SSB could have a similar effect on consumer demand for these beverages ${ }^{(16,17)}$. The potential benefits of large taxes (around 20\%) on SSB include a boost in consumption of beverages that have little or no added sugar such as milk and water ${ }^{(15-17)}$; a decrease in SSB and those beverages that put individuals at risk for obesity ${ }^{(15-17)}$; and an incentive for beverage companies to create products that are less detrimental to the health of consumers ${ }^{(15)}$. Higher SSB taxes would also serve as an opportunity for federal, state and municipal government to generate revenue to fuel health promotion and education campaigns ${ }^{(15)}$. Such large-scale taxes on SSB have been proposed in New York and Maine, among other places, but have often been vigorously opposed by the beverage industry ${ }^{(15,18)}$.

Although jurisdictions have considered taxes on SSB, there are few scholarly data available regarding the public's opinion on such taxes. One poll cites that $52 \%$ of New Yorkers would be in favour of a large tax on SSB; a number which rose to $72 \%$ when respondents were told that revenues from such a tax would be used to support obesity prevention programmes ${ }^{(18)}$. However, the literature does not show how the public would react to these proposed tax increases. To address gaps in our understanding regarding public attitude towards proposed taxes on SSB, we collected baseline data from a representative sample of adults across the USA to determine beverage consumption, knowledge about SSB and obesity, and anticipated reaction to a $20 \%$ tax on these products. We aimed to examine the following research questions:

1. What are SSB consumption patterns?

2. What are the characteristics of those who consume SSB?

3. What is the public's knowledge about links between obesity and SSB consumption and certain health conditions?

4. What is the public's level of support for an added $20 \%$ tax on SSB?

5. What is the public's anticipated reaction to such taxes?

\section{Methods}

A random-digit dialled telephone interview lasting $20 \mathrm{~min}$ was administered to a representative sample of 592 adults across the USA by the Survey Research and Data Acquisition Resource (SRDAR) at Roswell Park Cancer Institute. Data collection began in April 2009 and was completed in June 2010. The data were weighted to the age, race and gender distribution of the population of the USA. Because of the increasing percentage of households that have a cell phone only, we included a sample of cell phone numbers in our study. Respondents who completed the survey on a cell phone were sent a cheque for \$US 10 immediately after completing the survey. The response rate was $20 \%$ for the landline surveys and $34 \%$ for the cell phone surveys, calculated with the American Association for Public Opinion Research response rate $\# 4^{(19)}$.

\section{Measures}

\section{Beverage consumption}

Sugar-sweetened beverages. To assess levels of consumption of SSB, we asked three survey questions: (i) 'In the past week approximately how many servings of sugarsweetened beverages have you consumed over the entire week?'; (ii) 'In the past week approximately how many servings of regular soda have you consumed over the entire week?'; and (iii) 'In the past week, approximately how many servings of sweetened coffee or tea have you consumed over the entire week?'

Respondents were given a brief description of the categories of beverages that we were interested in. We asked about SSB such as Kool-Aid, Gatorade, lemonade, $\mathrm{Hi}-\mathrm{C}$, or sweetened iced tea. This also included energy drinks such as Red Bull. We defined a serving of SSB as 12 fluid ounces. A serving of soda was also defined as 12 fluid ounces, which is the amount in one can of soda. A serving of coffee was defined as 6 fluid ounces, about the size of a small coffee cup that many people would use at home.

We calculated an overall average number of SSB consumed over the past week which included each of these. We then calculated a second average of pre-packaged SSB consumed over the past week. Pre-packaged SSB include sodas and other beverages that are sweetened when purchased. We excluded sweetened coffee and tea from this group, because some people make coffee or tea at home and add sugar themselves. This presumably would not be included in any proposed taxes on SSB.

Unsweetened beverages. To assess levels of consumption of unsweetened beverages, we asked the following survey question: 'In the past week approximately how many servings of $100 \%$ fruit or vegetable juice have you consumed over the entire week?' The same question format was repeated to ask about diet soda, milk (2\%, $1 \%$, skimmed and soya milk), unsweetened coffee or tea, tap water and bottled water.

Respondents were given a brief description of the categories of beverages that we were interested in. We asked about $100 \%$ fruit or vegetable juice with no sugar added, such as orange and grapefruit juice, or V8 vegetable juice. 
We define a serving of $100 \%$ fruit of vegetable juice as a half a cup, or 4 fluid ounces, and asked respondents not to count drinks such as Kool-Aid, Gatorade, cranberry juice cocktail or fruit punch. We asked about diet soda, and drinks made with artificial sweeteners such as sugar-free Red Bull and Crystal Light. A serving was defined as 12 fluid ounces, which is the amount in one can of soda. The number of drinks was recorded for each of the questions. We calculated an overall average number of unsweetened beverages consumed over the past week which included each of these.

Alcohol. We defined a drink of alcohol as one can or bottle of beer, one glass of wine, one can or bottle of wine cooler, one cocktail or one shot of liquor. Frequency of drinking alcoholic beverages was measured with the question: 'In the past week, approximately how many alcoholic beverages have you consumed over the entire week?' The number of drinks was recorded.

\section{Knowledge and attitudes}

To assess levels of knowledge about the health effects of obesity and soda consumption, respondents were asked whether each of the following statements was true or false, 'Frequent consumption of sweetened soft drinks increases the risk of...': '...obesity' (true or false), '... diabetes' (true or false), '...cavities among children' (true or false). Respondents were also asked to tell whether they thought obesity is related to: 'Diabetes' (yes or no), 'Heart disease' (yes or no), 'Asthma' (yes or no), 'Hypertension' (yes or no) and 'Cancer' (yes or no).

To assess attitudes about taxing SSB, respondents were asked, 'What would you do if your state began collecting a $20 \%$ tax on regular soda and sugar sweetened beverages?' Response choices were: 'No impact at all'; 'I'd switch to untaxed drinks, like diet soda, fruit juice, water, or milk'; 'I'd cut back on my soda and sweetened beverage consumption'. We also asked, 'Do you support or oppose a tax on regular soda and sweetened fruit drinks?' Response choices were: 'Strongly support'; 'Support'; 'Oppose'; 'Strongly oppose'.

\section{Other covariates}

Demographic covariates included sex (male $v$. female), age in years (18-24v. 25-44v. 45-64v. 65+), race/ethnicity (white, black, Hispanic, other), income ( $<$ \$US 17500, \$US 17501-40 000, \$US $40001-65000$, >\$US 65000 ), education (less than 12 years, high-school graduate or GED (General Educational Development), some college, college graduate or more) and BMI (underweight, healthy weight, overweight, obese). Respondents were asked for their height and weight, which were used to calculate an estimated BMI (since under-reporting is likely) ${ }^{(20)}$; a BMI of $<18.5 \mathrm{~kg} / \mathrm{m}^{2}$ is underweight, $18.5-24.9 \mathrm{~kg} / \mathrm{m}^{2}$ is considered a healthy weight, $25 \cdot 0-29 \cdot 9 \mathrm{~kg} / \mathrm{m}^{2}$ is overweight and $\geq 30 \cdot 0 \mathrm{~kg} / \mathrm{m}^{2}$ is obese.

\section{Statistical analysis}

Statistical analyses were conducted using the SPSS statistical software package version $14 \cdot 0$ (SPSS Inc., Chicago, IL, USA). Descriptive statistics were conducted for measures of beverage consumption and measures of support for a $20 \%$ tax on SSB. Logistic regression analyses were used to examine the correlates of drinking SSB while controlling for the covariates. We also used logistic regression to examine the association between SSB consumption and knowledge about the health effects of SSB and the health effects of obesity, as well as the association between demographic measures and support for a $20 \%$ tax on SSB. Analysis results were weighted to the demographics of the population within the USA.

\section{Results}

The characteristics of the sample are included in Table 1. The respondents who completed the survey on a cell phone were more likely to be younger, male and African American, compared with the respondents who completed the survey on a landline phone. A high proportion of adults in our sample (69\%) reported drinking at least one pre-packaged SSB in the last week. Among those who consumed a SSB in the last week, the average number of pre-packaged SSB that respondents reported drinking per week was 6.9; respondents reported drinking forty-five servings of unsweetened beverages (including bottled water and tap water) during the past week and 3.6 servings of alcoholic beverages.

Logistic regression analyses were used to examine the correlates of drinking SSB while controlling for gender, age, BMI, race, education and income. Respondents most likely to report drinking an SSB in the past week were African Americans, males, those age 18-24 years, those with a BMI of $\geq 30.0 \mathrm{~kg} / \mathrm{m}^{2}$ and those with lower levels of education $(P<0 \cdot 05$; Table 2$)$. We also conducted a linear regression model (data not shown) assessing the number of SSB reported per week, among those who reported any consumption, with results similar to the logistic regression except that the association of SSB consumption with race and with education disappeared using this method.

The majority of survey respondents knew that frequent consumption of soft drinks increases the risk of obesity (91\%), diabetes (90\%) and dental cavities among children (94\%; data not shown). However, fewer respondents knew that obesity is related to diabetes $(79 \%)$, heart disease (89\%), asthma (36\%), hypertension (75\%) or cancer (44\%). Respondents who reported consuming SSB in the last week were less likely to report that obesity is related to these conditions than were respondents who reported drinking no SSB in the last week; however, these differences were not statistically significant (Fig. 1).

Respondents were asked to consider what they would do if their state began collecting a $20 \%$ tax on regular soda and SSB. Thirty-seven per cent said that it would 
Table 1 Characteristics of the respondents by type of phone (landline $v$. cell): random-digit dialled telephone sample of US adults ( $n$ 592), April 2009-June 2010

\begin{tabular}{|c|c|c|c|c|c|c|}
\hline & \multicolumn{2}{|c|}{ Landline } & \multicolumn{2}{|c|}{ Cell phone } & \multicolumn{2}{|c|}{ Combined data } \\
\hline & $n$ & $\%$ & $n$ & $\%$ & $n$ & $\%$ \\
\hline \multicolumn{7}{|l|}{ Gender } \\
\hline Male & 158 & $40 \cdot 9$ & 119 & $57 \cdot 8^{*}$ & 277 & $46 \cdot 8$ \\
\hline Female & 228 & $59 \cdot 1$ & 87 & $42 \cdot 2^{*}$ & 315 & $53 \cdot 2$ \\
\hline \multicolumn{7}{|l|}{ Age (years) } \\
\hline $18-24$ & 19 & 4.9 & 51 & $24 \cdot 9^{*}$ & 70 & $11 \cdot 8$ \\
\hline $25-44$ & 137 & $35 \cdot 4$ & 102 & $49 \cdot 8^{\star}$ & 239 & $40 \cdot 3$ \\
\hline $45-64$ & 140 & $36 \cdot 2$ & 43 & $21 \cdot 0^{*}$ & 183 & $31 \cdot 0$ \\
\hline $65+$ & 91 & $23 \cdot 5$ & 9 & $4 \cdot 4^{\star}$ & 100 & $16 \cdot 9$ \\
\hline \multicolumn{7}{|l|}{$\mathrm{BMI}$} \\
\hline Healthy weight or underweight & 149 & $40 \cdot 8$ & 76 & $37 \cdot 6$ & 225 & $39 \cdot 7$ \\
\hline Overweight & 113 & $31 \cdot 0$ & 68 & $33 \cdot 7$ & 181 & 31.9 \\
\hline Obese & 103 & $28 \cdot 2$ & 58 & $28 \cdot 7$ & 161 & $28 \cdot 5$ \\
\hline \multicolumn{7}{|l|}{ Race } \\
\hline White & 298 & $79 \cdot 3$ & 140 & $69 \cdot 0^{*}$ & 438 & $75 \cdot 7$ \\
\hline Black & 31 & $8 \cdot 2$ & 31 & $15 \cdot 3^{\star}$ & 62 & $10 \cdot 7$ \\
\hline Hispanic & 22 & $5 \cdot 9$ & 16 & $7 \cdot 9^{\star}$ & 38 & $6 \cdot 6$ \\
\hline Other & 25 & $6 \cdot 6$ & 16 & $7 \cdot 9^{*}$ & 41 & $7 \cdot 0$ \\
\hline \multicolumn{7}{|l|}{ Education } \\
\hline Less than 12 years & 33 & $8 \cdot 6$ & 15 & $7 \cdot 3$ & 48 & $8 \cdot 2$ \\
\hline High-school graduate or GED & 89 & $23 \cdot 2$ & 64 & $31 \cdot 1$ & 153 & $25 \cdot 9$ \\
\hline Some college & 109 & $28 \cdot 5$ & 61 & $29 \cdot 6$ & 170 & $28 \cdot 8$ \\
\hline College graduate or more & 152 & $39 \cdot 7$ & 66 & $32 \cdot 0$ & 218 & $37 \cdot 0$ \\
\hline $\begin{array}{l}\text { Income } \\
\quad<\$ \cup S 17500\end{array}$ & 43 & $11 \cdot 5$ & 27 & $13 \cdot 6$ & 70 & $12 \cdot 2$ \\
\hline \$US $17501-40000$ & 76 & $20 \cdot 3$ & 35 & $17 \cdot 7$ & 111 & $19 \cdot 4$ \\
\hline \$US $40001-65000$ & 73 & $19 \cdot 5$ & 40 & $20 \cdot 2$ & 113 & $19 \cdot 7$ \\
\hline$>$ SUS 65000 & 135 & $36 \cdot 0$ & 82 & $41 \cdot \overline{4}$ & 217 & $37 \cdot 8$ \\
\hline Refused & 48 & $12 \cdot 8$ & 14 & $7 \cdot 1$ & 62 & $10 \cdot 9$ \\
\hline
\end{tabular}

GED, General Educational Development.

${ }^{*}$ Proportion was significantly different from that in the landline phone group $\left(\chi^{2}\right.$ test): $P<0.05$.

have no impact at all, $20 \%$ said that they would switch to untaxed drinks (e.g. diet soda and fruit drinks) and 39\% said that they would cut back on their consumption of SSB. Four per cent responded that they did not know what they would do (data not shown).

Overall, 36\% of respondents supported the implementation of a tax on pre-packaged SSB, with greatest support among those aged 18-24 years, those with BMI $<30 \mathrm{~kg} / \mathrm{m}^{2}$ and those with higher levels of education $(P<0 \cdot 05$; Table 3$)$. Also, those who responded to the survey on their cell phone were more likely to support a tax on SSB (44\%) than those who responded to the survey on a landline phone (32\%, $P<0.05$ from $\chi^{2}$ test; data not shown).

\section{Discussion}

The main finding from this nationally representative survey is that SSB consumption is high among adults, and that there exists a sizeable minority of the population that favours implementing a tax on SSB. This suggests that such a tax may in fact reduce consumption among some people, in addition to generating revenue for obesity prevention and health education.

We found that $69 \%$ of adults surveyed reported drinking SSB in the past week, which is consistent with previous research; about two-thirds of adults report regular consumption of $\mathrm{SSB}^{(9,10)}$. In fact, Bleich et al. ${ }^{(9)}$ reported that consumption has increased over the past decade, concurrent with rising rates of obesity ${ }^{(11)}$ and type 2 diabetes $^{(21)}$. In our survey, adults reported consuming seven $12 \mathrm{oz}$ servings of SSB per week, which according to other studies ${ }^{(11)}$ appears to be an underestimation of true consumption.

Our analysis shows the highest reported consumption of SSB among African Americans, those with a BMI of $\geq 30.0 \mathrm{~kg} / \mathrm{m}^{2}$ and those with lower levels of education. Previous research has shown that minority and low socio-economic groups are disproportionately affected by obesity $^{(11,21)}$ and type 2 diabetes $^{(21)}$. However, this population subgroup is also the least likely to support a tax on SSB. When conducting a linear regression model (data not shown) assessing the number of SSB reported per week among SSB consumers, we found that the association of SSB consumption with race and with education disappeared. Therefore, we concluded that the association between SSB consumption and race and education is more a function of the decision to consume SSB at all, rather than an effect on increasing levels of consumption.

The response rate for the cell phone sample was higher (34\%) than for the landline phone sample (20\%). This is not surprising, because it is more likely when calling cell 
Table 2 Odds of reporting consumption of pre-packaged sugar-sweetened beverages in the past week: random-digit dialled telephone sample of US adults ( $n$ 592), April 2009-June 2010

\begin{tabular}{|c|c|c|c|c|c|}
\hline & \multicolumn{2}{|c|}{ Consumption } & \multirow[b]{2}{*}{ OR } & \multicolumn{2}{|c|}{$95 \% \mathrm{Cl}$} \\
\hline & Total $n$ & $\%$ Yes & & Lower & Upper \\
\hline Overall & & $69 \cdot 4$ & & & \\
\hline \multicolumn{6}{|l|}{ Gender } \\
\hline Male & 277 & $75 \cdot 1$ & $1 \cdot 0$ & \multicolumn{2}{|c|}{ Referent } \\
\hline Female & 315 & $64 \cdot 1$ & 0.7 & $0 \cdot 46$ & $1 \cdot 06$ \\
\hline \multicolumn{6}{|l|}{ Age (years) } \\
\hline $18-24$ & 70 & $91 \cdot 4$ & $1 \cdot 0^{\star}$ & \multicolumn{2}{|c|}{ Referent } \\
\hline $25-44$ & 239 & $75 \cdot 5$ & $0 \cdot 4$ & $0 \cdot 13$ & 0.93 \\
\hline $45-64$ & 183 & $65 \cdot 4$ & $0 \cdot 2$ & 0.09 & 0.66 \\
\hline $65+$ & 100 & $47 \cdot 5$ & $0 \cdot 1$ & 0.05 & $0 \cdot 37$ \\
\hline \multicolumn{6}{|l|}{ BMI } \\
\hline Healthy weight or underweight & 225 & $63 \cdot 8$ & $1 \cdot 0$ & \multicolumn{2}{|c|}{ Referent } \\
\hline Overweight & 181 & $68 \cdot 9$ & $1 \cdot 1$ & $0 \cdot 71$ & $1 \cdot 86$ \\
\hline Obese & 161 & $78 \cdot 9$ & $2 \cdot 1^{*}$ & $1 \cdot 23$ & $3 \cdot 60$ \\
\hline \multicolumn{6}{|l|}{ Race } \\
\hline White & 438 & $66 \cdot 7$ & $1 \cdot 0$ & \multicolumn{2}{|c|}{ Referent } \\
\hline Black & 62 & $87 \cdot 1$ & $2 \cdot 9^{*}$ & $1 \cdot 20$ & $7 \cdot 11$ \\
\hline Hispanic & 38 & $76 \cdot 3$ & $1 \cdot 2$ & 0.50 & $2 \cdot 81$ \\
\hline Other & 41 & $74 \cdot 4$ & 1.5 & 0.69 & $3 \cdot 49$ \\
\hline \multicolumn{6}{|l|}{ Education } \\
\hline Less than 12 years & 48 & $78 \cdot 7$ & $1 \cdot 0$ & \multicolumn{2}{|c|}{ Referent } \\
\hline High-school graduate or GED & 153 & $78 \cdot 9$ & $0 \cdot 8$ & $0 \cdot 29$ & $2 \cdot 04$ \\
\hline Some college & 170 & $66 \cdot 7$ & $0 \cdot 3^{*}$ & $0 \cdot 13$ & $0 \cdot 89$ \\
\hline College graduate or more & 218 & $61 \cdot 9$ & $0 \cdot 3^{*}$ & $0 \cdot 12$ & $0 \cdot 84$ \\
\hline \multicolumn{6}{|l|}{ Income } \\
\hline$<\$ U S 17500$ & 70 & $73 \cdot 5$ & $1 \cdot 0$ & \multicolumn{2}{|c|}{ Referent } \\
\hline \$US 17501-40000 & 111 & $67 \cdot 6$ & $0 \cdot 8$ & 0.39 & $1 \cdot 85$ \\
\hline \$US $40001-65000$ & 113 & $69 \cdot 9$ & 1.6 & $0 \cdot 70$ & $3 \cdot 46$ \\
\hline$>\$$ US 65000 & 217 & $70 \cdot 5$ & 1.5 & $0 \cdot 70$ & 3.35 \\
\hline Refused & 63 & $57 \cdot 1$ & $1 \cdot 0$ & $0 \cdot 40$ & $2 \cdot 61$ \\
\hline \multicolumn{6}{|l|}{ Phone } \\
\hline Landline & 387 & $62 \cdot 2$ & $1 \cdot 0$ & \multicolumn{2}{|c|}{ Referent } \\
\hline Cell phone & 206 & $82 \cdot 8$ & $1 \cdot 6$ & 0.95 & $2 \cdot 53$ \\
\hline
\end{tabular}

GED, General Educational Development.

${ }^{*} \mathrm{OR}$ and $95 \% \mathrm{Cl}$ were significant in a logistic regression model controlling for each variable presented in the table: $P<0.05$.

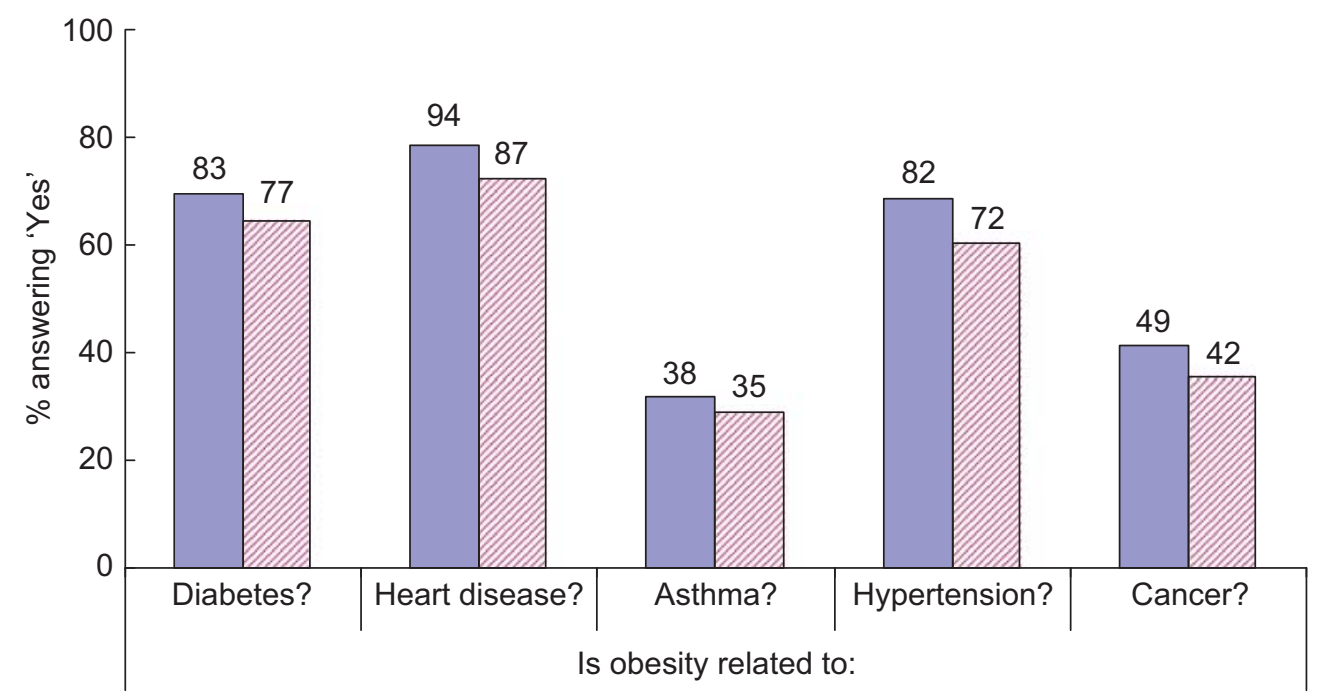

Fig. 1 (colour online) Knowledge about health effects related to consumption of sugar-sweetened beverages (SSB) according to SSB consumption in the past week ( $\square$ (solid), no; $\square$ (hatched), yes) among a random-digit dialled telephone sample of US adults ( $n$ 592), April 2009-June 2010. None of the differences were statistically significant ( $\chi^{2}$ test)

phones to receive a 'Not in Service' message, which is classified as ineligible. Numbers classified as ineligible are not included in the calculation of the response rate. In our cell phone sample, $46 \%$ of the numbers dialled were classified as ineligible, compared with $22 \%$ of the landline numbers dialled. With regard to consumption, we found 
Table 3 Odds of reporting support for a tax on sugar-sweetened beverages: random-digit dialled telephone sample of US adults ( $n$ 592), April 2009-June 2010

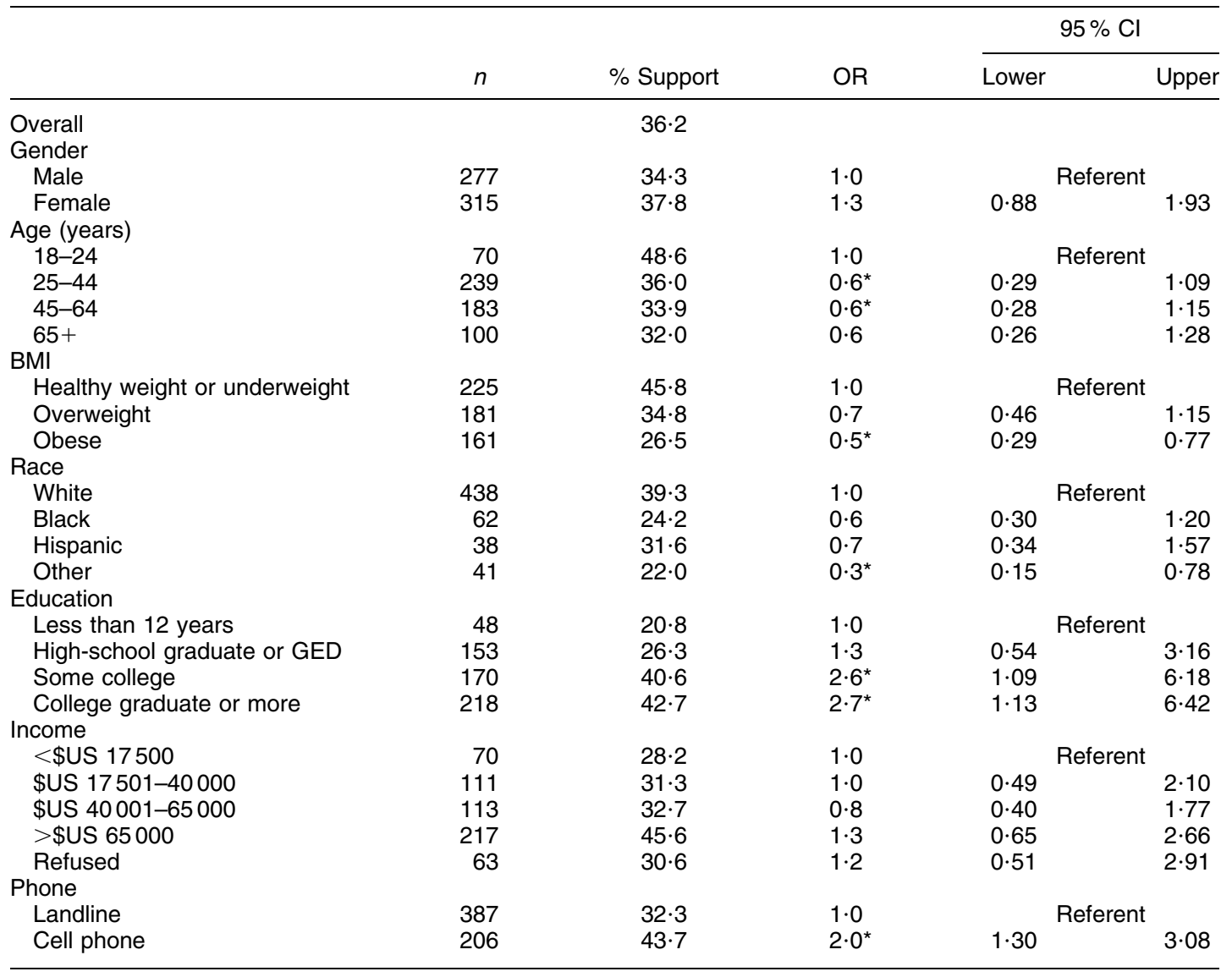

GED, General Educational Development.

${ }^{*} \mathrm{OR}$ and $95 \% \mathrm{Cl}$ were significant in a logistic regression model controlling for each variable presented in the table: $P<0.05$.

that differences observed between the cell phone and landline sample could be explained by differences in the demographics of these two samples. This is reinforced by the data showing that likely cell user demographics (younger, male, African American) coincided with likely SSB consumer demographics (age 18-24 years, African American, males, BMI of $\geq 30 \cdot 0 \mathrm{~kg} / \mathrm{m}^{2}$, lower education levels). According to our results, the respondents who completed the interview via cell phone were more likely to report consumption of SSB and more likely to support a tax on these beverages. We found some evidence that cell phone respondents were more likely to support an SSB tax, even after adjusting for demographic differences (data not shown). The addition of cell phone respondents makes the sampling frame more complete; thus, studies that do not include a cell phone component may be underestimating population support for an SSB tax.

Based on this survey of US adults, and conservatively estimating that each serving of SSB is $418 \mathrm{~kJ}$ (100 kcal), we estimated that 76 billion beverages are consumed annually, translating into $31 \cdot 8 \times 10^{12} \mathrm{~kJ}\left(7 \cdot 6 \times 10^{12} \mathrm{kcal}\right)$ per year from SSB alone. If a tax of $\$$ US $0 \cdot 01$ per ounce were implemented
(\$US $0 \cdot 12$ for each serving), over \$US 9 billion in revenue would be generated annually. Using some of that revenue to fund nutrition and physical activity education would further help to combat obesity in the USA.

The present study has several limitations. First, our use of self-reported data may raise concern because of underreporting. However, previous research has found that adults under-report their dietary consumption by as much as $25 \%{ }^{(20)}$, and may do so more often for foods containing fats and sugars ${ }^{(22)}$. Therefore, if there are inaccuracies, it is most likely that consumption of SSB is even higher than we reported. Second, our sample size was relatively small, which may limit the power of our analyses. However, the data are weighted to the demographic population of the USA. In order to increase the representativeness of our findings, we also included respondents who have only a cell phone and not a landline phone, as research has demonstrated a coverage error that may occur in telephone surveys that use only a landline frame, particularly for younger and lower-income adults ${ }^{(23)}$. Finally, although we predict that a tax on SSB may reduce consumption, the actual impact of such a tax is unclear until it is 
implemented and evaluated. However, Finkelstein et al. ${ }^{(24)}$ have noted the relationship between SSB intake, overall energy intake and rising obesity trends over time in their discussion of the economic impact of obesity in the USA. The authors note that a sizeable majority of health costs associated with obesity are levied by taxpayers, which serve as a motivator for government to reduce costs associated with this issue. Even if consumption was reduced by only modest amounts, the revenue potential of such a tax implication could be used to subsidize taxpayer burden of obesity costs ${ }^{(24)}$. Other researchers have proposed that tax revenue could be used to fund public education campaigns designed to highlight the health issues related to obesity, to point out of the sugar content of various beverages, and to raise awareness of the potential health impacts of consuming $\mathrm{SSB}^{(25)}$. Such a campaign, in the presence of an SSB tax, could have a synergistic effect on beverage consumption.

In summary, these data suggest that a large majority of US adults regularly consume SSB and that a tax on these beverages may be helpful to decrease consumption. Opportunities also exist for educating the public about the health effects of obesity and the risks associated with frequent SSB consumption.

\section{Acknowledgements}

This project was provided by the SRDAR at Roswell Park Cancer Institute. The authors have no conflicts of interest. A.H., C.R. and S.E.M. designed the research, C.R. and D.S. conducted the research, C.R. and D.S. analysed the data, C.R., D.S., S.E.M. and A.H. wrote the paper, and C.R. had primary responsibility for the final content. All authors read and approved the final manuscript.

\section{References}

1. Malik VS, Popkin BM, Bray GA et al. (2010) Sugar-sweetened beverages, obesity, type 2 diabetes mellitus, and cardiovascular disease risk. Circulation 121, 1356-1364.

2. Chen L, Caballero B, Mitchell DC et al. (2010) Reducing consumption of sugar-sweetened beverages is associated with reduced blood pressure: a prospective study amongst United States adults. Circulation 121, 2398-2406.

3. Renehan AG, Tyson M, Egger M et al. (2008) Body-mass index and incidence of cancer: a systematic review and meta-analysis of prospective observational studies. Lancet 371, 561-578.

4. National Cancer Institute (2004) Fact Sheet; Obesity and Cancer: Questions and Answers. http://www.cancer.gov/ cancertopics/factsheet/Risk/obesity (accessed October 2010).

5. Goldman D, Michaud CP, Lakdawalla D et al. (2010) The fiscal consequences of trends in population health. Natl Tax J 63, 307-330.
6. Olsen NJ \& Heitman BL (2008) Intake of calorically sweetened beverages and obesity. Obes Rev 10, 68-75.

7. Vartanian LR, Schwartz MB \& Brownell KD (2007) Effects of soft drink consumption on nutrition and health: a systematic review and meta-analysis. Am J Public Health 97, 667-675.

8. Division of Nutrition and Physical Activity, Centers for Disease Control and Prevention (2006) Does Drinking Beverages with Added Sugars Increase the Risk of Overweight? Research to Practice Series no. 3. Atlanta, GA: CDC.

9. Bleich SN, Wang YC, Wang Y et al. (2009) Increasing consumption of sugar-sweetened beverages among US adults: 1988-1994 to 1999-2004. Am J Clin Nutr 89, 372-381.

10. Finkelstein EA, Zhen C, Nonnemaker J et al. (2010) Impact of targeted beverage taxes on higher- and lower-income households. Arch Intern Med 170, 2028-2034.

11. Wang Y \& Beydoun MA (2007) The obesity epidemic in the United States - gender, age, socioeconomic, racial/ethnic, and geographic characteristics: a systematic review and meta-regression analysis. Epidemiol Rev 29, 6-28.

12. Chan RS \& Woo J (2010) Prevention of overweight and obesity: how effective is the current public health approach. Int J Environ Res Public Health 7, 765-783.

13. Jacobson MF \& Brownell KD (2000) Small taxes on soft drinks and snack foods to promote health. Am J Public Health 90, 854-857.

14. Powell LM \& Chaloupka FJ (2009) Food prices and obesity: evidence and policy implications for taxes and subsidies. Milbank Q 87, 229-257.

15. Brownell KD, Farley T, Willett WC et al. (2009) The public health and economic benefits of taxing sugar-sweetened beverages. $N$ Engl J Med 361, 1599-1605.

16. Frieden TR (2010) A framework for public health action: the health impact pyramid. Am J Public Health 100, 1541-1548.

17. Andreyeva T, Long MW \& Brownell KD (2010) The impact of food prices on consumption: a systematic review of research on the price elasticity of demand for food. $A m J$ Public Health 100, 216-222.

18. Brownell KD \& Frieden TR (2009) Ounces of prevention the public policy case for taxes on sugared beverages. $N$ Engl J Med 360, 1805-1808.

19. American Association for Public Opinion Research (2008) Standard Definitions: Final Dispositions of Case Codes and Outcome Rates for Surveys, 5th ed. Lenexa, KS: AAPOR.

20. Bingham SA, Gill C, Welch A et al. (1994) Comparison of dietary assessment methods in nutritional epidemiology: weighed records v. $24 \mathrm{~h}$ recalls, food-frequency questionnaires and estimated-diet records. Br J Nutr 72, 619-643.

21. Mokdad AH, Ford ES, Bowman BA et al. (2003) Prevalence of obesity, diabetes, and obesity-related health risk factors, 2001. JAMA 289, 76-79.

22. Bingham SA (1994) The use of 24-h urine samples and energy expenditure to validate dietary assessments. $\mathrm{Am} \mathrm{J}$ Clin Nutr 59, 1 Suppl., 227S-231S.

23. Lavrakas PJ, Shuttles CD, Steeh C et al. (2007) The state of surveying cell phone number in the United States: 2007 and beyond. Public Opin Q 71, 840-854.

24. Finkelstein EA, Ruhm CJ \& Kosa KM (2005) Economic causes and consequences of obesity. Annu Rev Public Health 26, 239-257.

25. Hattersley L, Irwin M, King L et al. (2009) Determinants and patterns of soft drink consumption in young adults: a qualitative analysis. Public Health Nutr 12, 1816-1822. 